\title{
International Standards in Prevention: How to influence Prevention Systems by Policy Interventions?
}

\author{
Gregor Burkhart
}

European Monitoring Centre for Drugs and Drug Addiction (EMCDDA)

Lisbon, Portugal.

Correspondence email: gregor.burkhart@emcdda.europa.eu

\begin{abstract}
The existence of multiple standards for drug prevention, published by different national and international organisations, might seem redundant and confusing at a glance. This paper aims to explain the rationales of the different standards and that they differentially respond to specific challenges of each of the three main components of a prevention system: interventions, services and people. Effectiveness of standards can improve the effectiveness of programmes and interventions, while process standards can improve the context within which effective programmes and interventions are implemented. The variety of the existing standards and their different levels of exigencies can be beneficiary if policy makers apply them in combination - ie. choosing effective interventions and assuring that they are properly implemented and accepted, and in the appropriate cultural and geographic context. Other international organisations involved provide additional support such as certified training and online resources. Taken together, these initiatives might pave the way for setting up accreditation systems, in some countries, and help to assure that prevention providers take up such effective interventions and that prevention professionals are capable of implementing and willing to use it. All this requires, however, the political will to actually implement these standards since it implies revising, challenging and improving customary prevention systems with traditional approaches.
\end{abstract}


المعايير الدولية للوقاية: كيف يتم التأثير على الأنظمة الوقائية عن طريق التدخل السياساتي؟

$$
\text { جريجور بوركهارت المرصد الأوربي للمخدرات و إدمان المخدرات }
$$

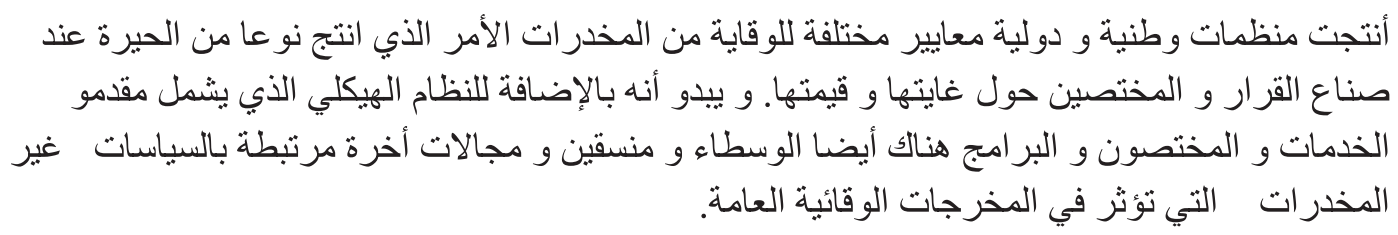

تركز هذه الورقة البحثية على كيف يمكن للتدخل السياساتي كالمعايير الوقائية دعم الأعمدة الثثلاث للأنظمة

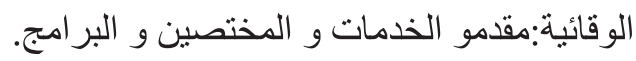

Keywords: Prevention Systems, Drug prevention

In recent years a number of international and national organisations ${ }^{1}$ have produced different standards in the field of drug prevention. This has led to a certain degree of confusion among policy-makers and professionals about the purpose and differential value of each of them, and there is an impression of overlap and duplication of efforts.

In order to understand each standard's added value and the potential for synergy of all of them taken together, this paper will describe each of them from the perspective of prevention systems. The simplified term "drug prevention" is used here to cover a whole range of prevention objectives, hence not solely to prevent substance use, but also to delay initiation, reduce its intensification or prevent escalation into problem use.

\section{What are prevention systems?}

Contrary to common beliefs, it is not sufficient to have effective interventions at hand in order to achieve successful prevention efforts. Rather, at

1 UNODC (United Nations Office on Drugs and Crime - www.unodc.org)

CCSA (Canadian Centre for Substance Abuse - http://ccsa.ca)

The European Prevention Standards Partnership's EDPQS (European Drug Prevention Quality Standards - www.prevention-standards.eu) initiative in collaboration with the EMCDDA (European Monitoring Centre for Drugs and Drug Addiction - www.emcdda.europa.eu)

COPOLAD (Cooperation Programme on Drugs Policies between Latin America and the European Union - www.copolad.eu)

CICAD (Inter-American Drug Abuse Control Commission - www.cicad.oas.org)

The US-American SPR (Society for prevention research - www.preventionresearch.org) 
the population level, the understanding and development of implementation factors such as policy, structure, organisation, workforce, prevention ethos and culture may be more important than identifying effective interventions (Ritter \& McDonald 2008). It seems that important clues for understanding the complexity of prevention systems apart from political will and effective interventions are factors such as how prevention is funded, whether quality criteria are linked to funding of programmes and organisations, how prevention policies are delivered in organisational terms (eg. fully decentralised at local level versus strong guidance and prescription from central levels), whether high quality training is part of the prevention policy implemented in each country, if there is a competent workforce to deliver evidence-based prevention, whether the different administrative sectors (education, health, youth, criminal justice) properly cooperate, if research centres are involved in evaluation and development, how much policy makers and professionals know about effective prevention principles, whether effective programmes are available, and if they can be implemented and rolled out.

Prevention systems and the interaction of their different components with other societal variables in achieving outcomes can be described in various, also graphical forms. Examples can be found in UNODC's International Standards for Drug Prevention ${ }^{2}$ or the following on the Website of the EMCDDA ${ }^{3}$.

Figure 1. A graphical example of a prevention system

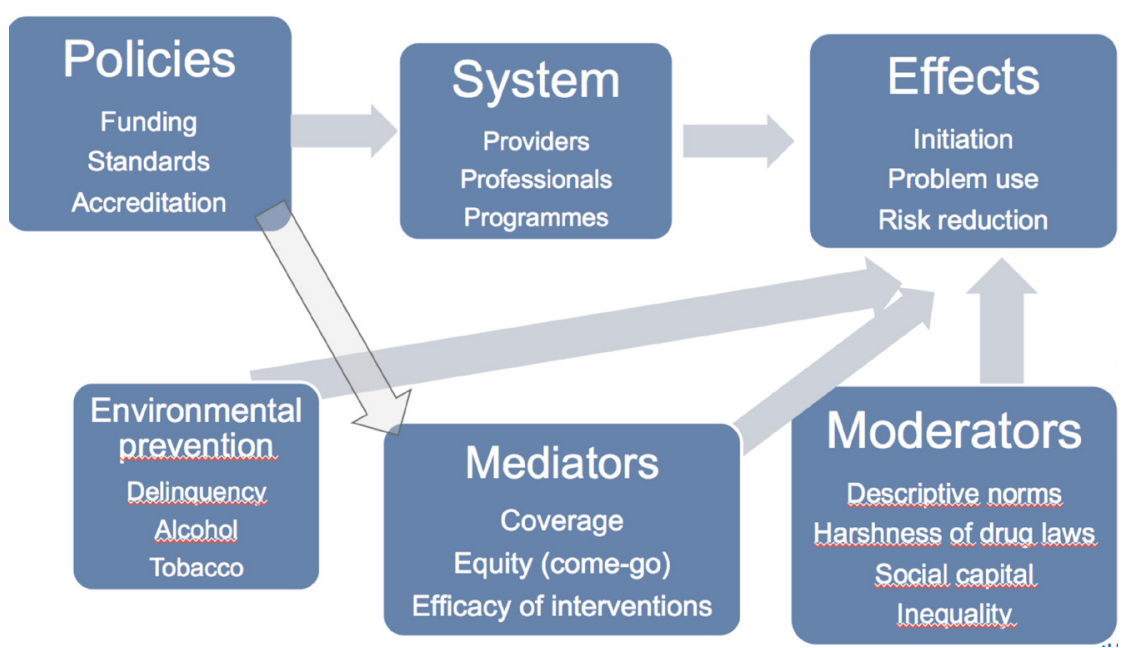

It appears that besides the structural system (providers, professionals and programmes) there are additional mediators (elements, whose modification

2 http://www.unodc.org/unodc/en/prevention/prevention-standards.html

3 http://www.emcdda.europa.eu/activities/expert-meetings/2013/prevention 
through policies change the overall effect), moderators (that affect overall effects without being easily modified), and other policy areas (ie. other than drugs) that influence the overall prevention outcomes at population level.

This paper focuses on the upper left quadrant of the graph: how policy interventions such as prevention standards might improve the three main pillars of prevention systems: providers, professionals and programmes.

Providers and facilities would be, for example, NGOs, associations, universities, schools, prevention centers, health centres or the police, depending on the country. Not only prevention specialists but professionals should also be considered but mostly teachers and educators, family counselors, staff in health, counseling and youth centres, policemen, outreach and social workers, and other professionals trained in delivering prevention.

The available programmes or interventions have to be analysed in terms of content and effectiveness, their timing within the human life cycle, their adequacy, relevance and feasibility for the target communities, their internal validity, ie. design, logic model and structure, and their level of evaluation and sustainability.

The features of these three structural main pillars of a prevention system strongly influence whether prevention can have an impact on risk behaviour and drug-related problems in a given country or region.

\section{The role of standards in prevention policies}

Even if many countries have national drug strategies that always include prevention and are, at least in Europe quite similar to each other, the delivery aspects of prevention policies differ enormously between countries since there are unlimited variations of funding, organisational responsibilities and of political competencies at different levels, depending on each country's organisational structure. Nevertheless, national and supra-national standards for prevention are important and feasible to apply since they provide common regional or international criteria that facilitate assessing the quality of professionals, services and interventions. Since in all cases they have been agreed with a wide range of different professional groups, in several waves and often across many countries, they can confidently be considered consensual common denominators for establishing "good quality" regarding content, design and implementation of prevention.

Notwithstanding these commonalities among the standards, each of them focuses on a different aspect of the three prevention system columns. This in turn makes them so complementary, for combined use. 
For instance some of the standards which address staff competencies ie. what do professionals have to know, what kind of training should they receive and what skills they need to have; while others focus on the design and infrastructure of interventions, ie. how to design interventions, how to adapt them, how to deliver them, whom to involve and consult and how to build sustainable infrastructures for them. Finally, some deal with the effectiveness of interventions and help to decide what kind of intervention to carry out, in what period of life and what seems to work best.

\section{Standards that address the contents and evidence-based of interventions}

The standards with the most exclusive and primordial focus on evidence-based practices (or, in simple words, the question: "what to do in prevention?") are the International Standards on Drug Use Prevention by UNODC $^{4}$ (Campello et al. 2014). They offer and promote strategies based on scientific evidence for working with families, schools, and communities, especially the most marginalised and poor. Their strength is that, for each developmental stage from early childhood to adulthood, and including workplaces, they summarise the currently available scientific evidence and describe interventions and policies that have been found to result in positive prevention outcomes and their characteristics. Also, they identify the major components and features of an effective national drug prevention system. Since their publication in 2013, regional and national seminars have been held in 60 countries with 200 policy makers and their work surveys.

They are available in English, Chinese, French, Russian, Spanish and Portuguese with the number of languages increasing.

Two of the standards presented in the following heading - the standards by CCSA and by COPOLAD - address the evidence of interventions as well, but with less preponderance.

\section{Standards about the design, implementation and infrastructure of prevention interventions}

The next group of standards is concerned with planning and adjusting interventions for prevention systems, inserting them into existing services and, partly, evaluating them or in simple words, answering the question: "how to do prevention?"

The standards that were most unequivocally set out for this purpose were those

4 http://www.unodc.org/unodc/en/prevention/prevention-standards.html 
of the European Drug Prevention Quality Standards Partnership (EDPQS) in close co-operation with the European Monitoring Centre for Drugs and Drug Addiction who published them (Brotherhood \& Sumnall 2011).

They are dealing with the processes of prevention, and their centerpiece is a project cycle (see below) aimed at improving each stage of a prevention implementation process.

\section{Figure 2. Structure of the EDPQS}

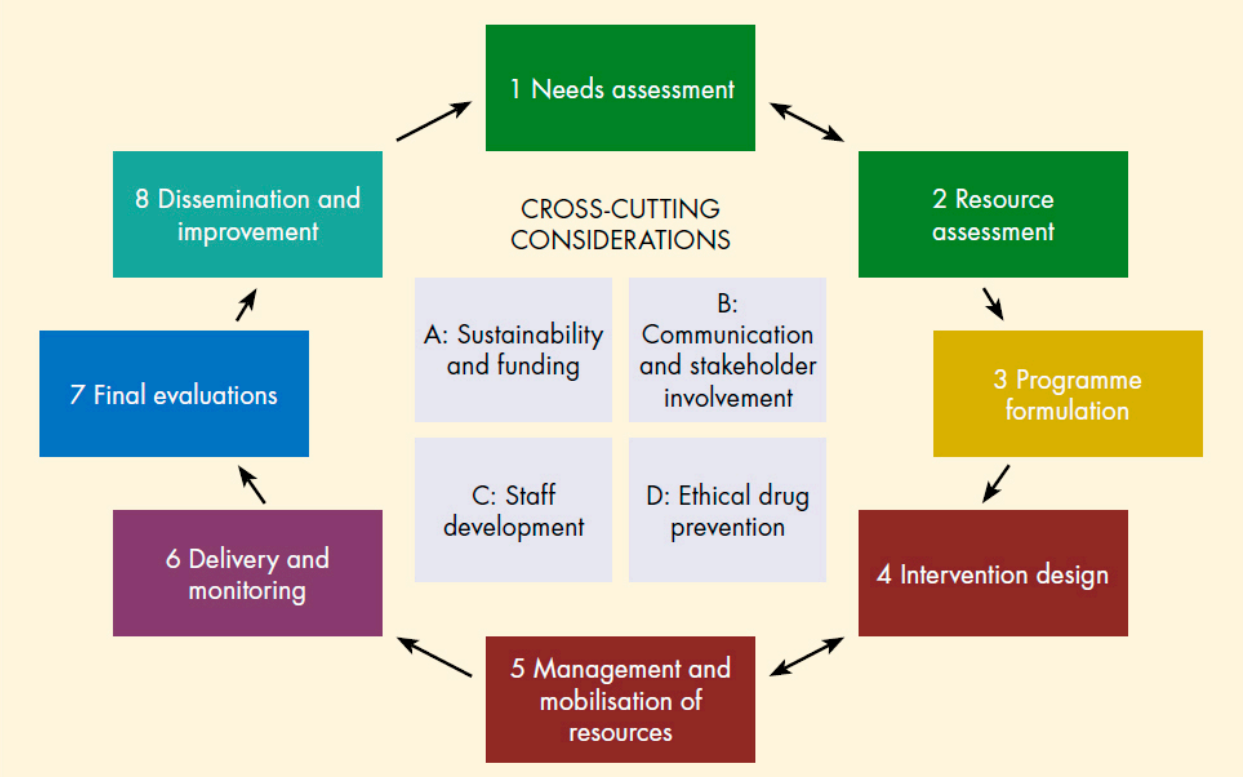

The standards were developed through a review of existing standards and a series of consultations. They provide reference points (benchmarks), which can be used to determine the quality of prevention activity or organisation. Such quality standards tend to focus on the implementation of policies and interventions, covering structural and procedural aspects such as staff composition, recruitment of target population, or evaluation. Therefore they do not prescribe the kind of intervention to be implemented, as in the UNODC standards, but rather refer to the context and the conditions within which interventions take place. They therefore complement the importance of considering what policies and interventions are effective with how such policies and interventions must be organised and delivered (eg. necessary infrastructures and governance structures).

The EDPQS standards draw the attention to understand "how people, programmes/interventions, organisations, and (governmental) strategies contribute towards drug prevention and to think about how existing efforts can be improved in order to obtain better and more sustainable results" (Broth- 
erhood \& Sumnall 2011). The EDPQS provides on its website ${ }^{5}$ an entire toolkit of materials for making the best use of the Standards; and the current Phase II of the European Drug Prevention Quality Standards Project produces case studies of how specific examples of drug prevention activities in the EU could benefit from using the standards, alongside a range of toolkits for practitioners, policy makers and their daily needs, in order to assess and promote the implementation of the standards in EU member states. The EDPQS main manual is available in English and a number of other European languages and support materials (self-checklist, mini-guides etc.) are downloadable in more than ten EU languages. The EDPQS has been used to inform the development of national and international standards, and are the only standards to offer guidance on the translation, adaptation and dissemination of quality standards in drug prevention.

A special feature that the EDPQS share with the COPOLAD (see below) standards is that they offer two different levels: a basic one, which all prevention activities should meet, and an expert one, which requires additional expertise or other resources. This strategy might set incentives for development and improvement.

Similar to the EDPQS, the Canadian Centre on Substance Abuse (CCSA) also offers on its website ${ }^{6}$ an entire Portfolio of Canadian Standards for Youth Substance Abuse Prevention, one each for community-based prevention, school-based prevention and for family-based prevention. These Standards provide the prevention teams in the country with guidance based on the best available evidence on how best to plan, select, implement and evaluate their prevention efforts. They were also a foundational piece used by the UNODC and by the European Prevention Standards Partnership to develop Standards.

The Canadian Standards include reviews of the evidence, but concentrate mainly on process aspects to pursue continuous improvement in order to focus existing resources on community needs and evidence-informed practices, to link with other initiatives in the community and to adapt to different regional contexts or populations. The Canadian standards are available in French and English and their implementation, usefulness and applicability in daily prevention practice is regularly monitored by the CCSA.

With a similar mix of contents, the COPOLAD standards (COPOLAD Programa de Cooperación entre América Latina y la Unión Europea en Políticas sobre Drogas 2014) focus on quality criteria of prevention programmes and their quality of evaluation and beyond that they aspire to provide criteria for the certification (accreditación) of programmes. As the EDPQS, they include a basic and an advanced level. The same publication also provides

5 http://prevention-standards.eu

6 http://CCSA.ca 
standards for harm reduction, treatment and re-integration of drug users, aiming to form an over-arching system to improve drug demand reduction in general in Ibero-American countries.

Also, the COPOLAD standards have passed through several phases of feedback and consultation with experts from Latin America and Europe. They are available in Spanish and Portuguese. Some countries in Latin America have volunteered to test the feasibility of introducing a national certification system for prevention programmes.

Standards of Evidence ${ }^{7}$ published by the 'American Society for Prevention Research' already in 2004 is a special case. They focus on the methodologies by which convincing evidence on the effectiveness of prevention programmes can be achieved, defining criteria for efficacy, effectiveness and dissemination. It is a consensus paper, ratified by the SPR board, which defines the scientific requirements of effective prevention programmes worthy of replication, adoption or dissemination. Its aim is to provide consistent and high standards for determining whether programmes have been scientifically shown to be efficacious, effective or ready for dissemination. Similar to the UNODC standards, their objective is to increase (policy makers') confidence in and commitment to the use of tested and effective policies, programmes and actions to promote positive youth development and prevent health and behaviour problems among young people. Considering the level of prevention practice and research in the majority of the world regions, its methodological requirements (eg. construct validity, reliability, clarity of causal inference, etc.) are very demanding and from a purely scientific realm. Their strength is nonetheless that they a) cover all areas of prevention, not only substance abuse, and b) have unified criteria for efficacy and effectiveness in prevention which since then have been widely used, for instance in the online registries of recommendable programmes mentioned below.

\section{Standards concerned with staff competencies}

While the COPOLAD standards and the EDPQS focus both on interventions (programmes) with an additional strong attention to staff development, it is the Minimum Quality Standards (MQS) by CICAD that have a main focus on staff competencies but also on the adaptation and implementation of programmes.

The CICAD MQS for prevention has been designed in order to provide the most basic criteria that could feasibly be applied in the hemisphere to Latin American countries and their explicit aim was to simplify and reduce the length, complexity and above all the exigencies of the European Drug Pre-

7 http://www.preventionresearch.org/StandardsofEvidencebook.pdf 
vention Quality Standards (EDPQS, EMCDDA, 2011) and the COPOLAD accreditation criteria for demand reduction programmes (COPOLAD Programa de Cooperación entre América Latina y la Unión Europea en Políticas sobre Drogas 2014). Another CICAD working group has produced standards for treatment.

Similar to others, CICAD's MQS give an overview on the theoretical underpinnings and characteristics of prevention interventions in the three main areas universal, selective and indicated prevention and define quality criteria for interventions. They list core principles such as ethics and a scientific approach, use of an overall strategy of continuous quality improvement, and sequenced implementation of a programme based on a needs assessment that prioritises problems and interventions. The MQS are not yet fully published but are purportedly going to form the basis for a minimal accreditation system for prevention professionals in South-America, to be tested and developed together with COPOLAD.

Table 1 provides a short synoptic view on the different features and main focus of the different standards. It seems to be visible that for each of the three pillars of a prevention system (organisations, programmes and professionals), at least one of these standards can be applied, depending on geographical context and infrastructural needs in order to achieve changes and improvements.

Table 1. Overview on current standards

\begin{tabular}{|c|c|c|c|c|c|}
\hline & Coverage & Levels & Areas & Targets & Language \\
\hline UNODC & World & n. a. & Prevention & $\begin{array}{l}\text { Evidence for } \\
\text { interventions }\end{array}$ & $\begin{array}{l}\text { EN ES PT } \\
\text { FR RU + }\end{array}$ \\
\hline EDPQS & Europe & $\begin{array}{l}\text { Basic + } \\
\text { Expert }\end{array}$ & Prevention & $\begin{array}{l}\text { Intervention de- } \\
\text { sign and process } \\
+ \text { Workforce }\end{array}$ & $\begin{array}{l}\mathrm{EN}+>10 \\
\text { languages }\end{array}$ \\
\hline CCSA & Canada & n. a. & Prevention & $\begin{array}{l}\text { Intervention de- } \\
\text { sign and process } \\
+ \text { Evidence }\end{array}$ & EN FR \\
\hline $\begin{array}{l}\text { COPO- } \\
\text { LAD }\end{array}$ & $\begin{array}{l}\text { Latin } \\
\text { America }\end{array}$ & $\begin{array}{l}\text { Basic + } \\
\text { Advanced }\end{array}$ & $\begin{array}{l}\text { Prevention } \\
\text { Treatment } \\
\text { Harm Reduc- } \\
\text { tion Reinte- } \\
\text { gration }\end{array}$ & $\begin{array}{l}\text { Intervention de- } \\
\text { sign and process } \\
+ \text { Evidence }\end{array}$ & ES PT \\
\hline CICAD & $\begin{array}{l}\text { South-Amer- } \\
\text { ica }\end{array}$ & Minimum & $\begin{array}{l}\text { Prevention } \\
\text { Treatment }\end{array}$ & $\begin{array}{l}\text { Intervention } \\
\text { process }+ \text { Work- } \\
\text { force }\end{array}$ & ES EN \\
\hline SPR & US & $\begin{array}{l}\text { Highly ad- } \\
\text { vanced }\end{array}$ & Prevention & $\begin{array}{l}\text { Evidence of } \\
\text { interventions }\end{array}$ & EN \\
\hline
\end{tabular}




\section{Using standards for improving prevention systems Improving inter- vention contents}

UNODC has set up a worldwide training initiative for policy-makers to prioritise evidence-based and effective programmes or least effective prevention principles in their funding and selection decisions. Up till now, the onetime prevention establishments in a number of countries has kept using obsolete (informative, persuasive, individualistic) approaches with the pretext that there wasn't any established evidence on what works or not in prevention. Currently, there is less doubt about the effectiveness of some prevention approaches, it seems easier to disseminate and promote effective programmes to practitioners and policy makers. The Prevention $\mathrm{Hub}^{8}$ by Mentor International is going to have an important role for this purpose.

More available evidence on effectiveness also opens more possibilities to restrict fundable prevention interventions only to some certified and effective ones, as the Czech Ministry for Education has recently set out (Pavlas Martanová 2012) to do.

Clearer knowledge of evidence has also led to an increase in online registries that contain evidence-based prevention programmes which are recommended for implementation in countries. Until some years ago there was only the SAMHSA's registry ${ }^{9}$ for the US and EDDRA ${ }^{10}$ deliberately much less rigorous for Europe. In addition, the Best Practice Portal ${ }^{11}$ of the EMCDDA has been compiling and updating information on the evidence-base of a range of demand reduction strategies.

Now there are online registries of effective interventions in Spain ${ }^{12}$, in Germany ${ }^{13}$, by Blueprints ${ }^{14}$ in the US and soon by Blueprints Europe ${ }^{15}$. Also Mentor International's Prevention Hub disseminates information about some evidence-based programmes.

These online collections of evidence-based examples mostly contain the same programmes and use the same effectiveness and quality criteria, even without having coordinated between them. This universality negates the argument that common minimal standards for prevention is not possible ${ }^{16}$ since there is no clear definition of "evidence-based".

\footnotetext{
$8 \mathrm{http}: / /$ preventionhub.org

9 http://www.nrepp.samhsa.gov

$10 \mathrm{http}: / / \mathrm{www} . e m c d d a . e u r o p a . e u /$ themes/best-practice/examples

$11 \mathrm{http}: / /$ www.emcdda.europa.eu/best-practice

$12 \mathrm{http}: / /$ www.prevencionbasadaenlaevidencia.net

$13 \mathrm{http}: /$ gruene-liste-praevention.de

$14 \mathrm{http}: / /$ www.blueprintsprograms.com

$15 \mathrm{http}: / /$ investinginchildren.eu/standards-evidence

16 This was the comment of one European country at a recent consultation with EU member states for defining minimum stan-
} 
However, these collections focus almost exclusively on efficacy; and even if some of them pay much attention to and provide criteria for cultural adaptability and system-readiness, the following caveats have to be kept in mind.

Even if efficacy criteria are likely to be transferable and almost universal, implementation and feasibility aspects are not, since they are specific for a given country or even a certain region, due to differences in school system, school culture, popular beliefs, contextual factors and family cultures. In other words, societies and prevention infrastructures are "complex systems" (Hawe et al. 2009) that do not behave in a linear and easily predictable fashion: a change in input (eg. providing a new and effective prevention intervention) does not lead to a proportional change in outcome (eg. behavioural change). This is because complex systems are composed of other complex systems such as human beings who very dynamically adapt (or resist) to changes in local environments and other inputs. A prevention system might therefore simply "absorb and swallow" an efficacious intervention without any detectable effect, if important variables of implementation processes are not taken into consideration. So does the success and positive outcomes of a prevention programme and prevention strategies overall depend largely on the skills, motivation, dedication and personality of the people who implement them and of the infrastructures (social, legislative, technical and physical) that support them (Burkhart 2013).

- Social infrastructures can be social capital or the social support system in communities.

- Laws and rules against the promotion or alcohol, tobacco, cannabis or antisocial behaviour are meant to be "legislative".

- Standards and quality criteria as well as professional cultures are examples of technical infrastructures.

- "Physical" means spaces, room, transportation and sometimes incentives such as food and babysitting.

Even interventions that are highly effective in efficacy studies do not yield results in large implementations if these two pillars of a prevention system are not well developed (Ritter \& McDonald 2008): infrastructures and professionals.

As a consequence, it is not of much help to have effective interventions if they cannot be introduced into complex systems such as national or local prevention infrastructures. This, in turn, makes process standards so important (ie. those that focus on implementation aspects). If prevention profes-

dards in demand reduction at EU policy level 
sionals and policy makers combine the effectiveness standards of UNODC with one of the process standards discussed here, this might largely improve the chances of effective interventions or strategies to be wider disseminated, to attain more political sustainability and better acceptance in communities, to be transferred into other countries and to work also in different contexts.

By using both kinds of Standards together, professionals can mould effective interventions to a particular community and its stakeholders and make them more palatable to them. For this purpose improving them and making them more effective prevention infrastructures need first to be analysed and adapted to. Otherwise, even proven effective interventions do not even make it over the borders of certain countries. It seems for example that particularly in countries with a pre-ponderance of psycho-analytically trained prevention professionals, all approaches are repudiated that could be marked as "behaviorist" or "normative" (Burkhart 2013). In a big country of Latin America the implementers of the Good Behavior Game (Kellam et al. 2014) had to change the packaging information of the intervention (description of theory base, working mode and objectives) in order to overcome the fierce resistance by the Ministry of Education which considered it behaviourist and manipulative and therefore unacceptable for the country's educational philosophy. The process standards described above in this paper are helpful to adapt to such situations. But they are also helpful for the second important aspect of an implementation system.

Some of the standards - EDPQS, CCSA, but above all those by CICAD - focus on development and competencies of prevention staff, since the attitudes, knowledge and skills of the prevention workforce are key determinants for the successful implementation of both interventions and policies.

In a recent article in The Lancet, the author (Horton 2014) postulates that in order to achieve safe, effective, patient-centered, efficient, timely, and equitable care, a revolution in the quality of care is needed, which would constitute "a third revolution in global health" but this depends on staff training and less on interventions. Often there is no relation between health outcomes and coverage with key interventions because the missing ingredient is quality of the care by the specialised workforce. This applies as well to prevention. A pivotal point here is however is that there is no agreed means to monitor quality.

As said above, the success of interventions (be it their acceptance by the target group or their outcomes) depends often to a great extent on the people who implement them. Several of the Standards presented here can be helpful to develop quality criteria and Standards for the very people who have a role relating to preventive interventions. In many countries there is no special 
training curriculum for the prevention workforce and also no syllabus of what prevention professionals ought to know and to master. There are two notable exceptions, though.

One is the International Centre for Education and Training of Addiction Professionals (ICCE) $)^{17}$ set up by the Colombo Plan ${ }^{18}$, which provides a sophisticated and up-to-date training curriculum for prevention and a two level accreditation system with further options for specialist accreditation. While it operates until now predominantly in the Asian region, it is likely to be adapted and introduced to South America and other regions in the near future.

Another noteworthy initiative is the accreditation system for prevention professionals developed in the Czech Republic. It defines and tests four levels of accredited professional competence in prevention and also the different job and responsibility profiles for each level (Charvát et al. 2012) attention is also paid to reinforcing the skills necessary for the actual work with the target groups. Simply put, the system prescribes with sufficient detail what level of prevention proficiency a professional must have in order to carry out specific tasks. Most meaningfully, the respective legislation for the system assumes that prevention can be harmful, since prevention acts without sufficient accreditation, they have no access to public schools and to students. This seems to be quite unique in the world, even if it only covers those prevention professionals acting within the education system. The marketing slogan for the general public also expresses that state organs are taking prevention seriously: "only the best preventionists for your children!" This contrasts refreshingly with the prevailing reality of policies that pay lip service to the importance of prevention but allow almost anybody to do anything that is believed to be "preventive" regardless of the evidence. It seems to be evident that standards for the prevention workforce development can have an important rule in further expanding such promising developments.

\section{Future directions}

After the first phase of developing standards in Europe, the authors of the EDPQS (Brotherhood \& Sumnall 2011) stated that their standards should not be used for certification or accreditation because for this purpose it would be necessary to take into account, for example, the applicability of the standards to local circumstances and the opportunity costs of choosing one programme over another. The current document does not provide guidance on how to make such complex decisions, and therefore using the standards for this purpose is discouraged (p. 30)".

17 http://www.colombo-plan.org/icce

18 www.colombo-plan.org 
But for the current phase of the EDPQS, there is an explicit aim "to make the standards useful as a contribution to other purposes, such as formal self assessments, funding decisions, or external accreditation".

One logical and organic step forward would be the development of certification and accreditation systems based on the different standards. In theory, all three components of a prevention system can be certified or accredited: individual professionals, prevention service providers (ie. organisations) and prevention programmes, provided the latter has a sufficient level of manualisation.

Frequently though, "certification" and "accreditation" are used interchangeably. In order to solve this, the ISO Council Committee on Conformity Assessment $(\mathrm{CASCO})^{19}$ has attempted to standardise the definitions:

- Accreditation is the procedure by which an authoritative body gives formal recognition that a body or person is competent to carry out specific tasks.

- Certification is the procedure by which a third party gives written assurance (certificate of conformity) that a product, process or service conforms to specified requirements.

Following this definition, prevention programmes would be certified while services and professionals are accredited. The prevention workforce might be improved continuing with a soft approach, whereby voluntary training with different content and main emphasis is offered by a variety of academic and non-academic institutions. This could be further bolstered by defining some common (ie. international) training outcome criteria based on the standards. This would set the bar higher for the professionalisation of prevention professionals. The ultimate step would be to permit authorisation only to the accredited prevention professionals to do prevention work. In the treatment and medical field this is taken for granted, but rarely so in the prevention field.

Such a requirement however implies that there is sufficient number of professionals whose knowledge and skills could be accredited. In many regions of the world this might not be the case, since training possibilities are too scarce. The operational consequence of this is that at least two levels of accreditation of the prevention workforce are needed:

1. A very basic level for those prevention professionals who would only implement evidence-based programmes or parts of them and who by profession might not entirely be dedicated to prevention work: teach-

19 www.iso.org/iso/Casco 
ers and headmasters, family and youth workers, voluntary community members and the like. The shorter and basic training for these professionals might be easier to implement in large scale in a number of countries. The Prevention $\mathrm{Hub}^{20}$ of Mentor International could possibly be a platform for clustering and offering the respective training possibilities, partly online. The National Prevention Hubs would feature as multilingual and culture-sensitive local versions of it, usually helping to increase ability and ownership.

2. A more advanced level of prevention professionals might have to be developed or improved to monitor prevention programmes, or to plan prevention strategies and to commission programmes and services: local decision makers, city councilors, headmasters, prevention coordinators, service and programme managers or those professionals who are going to carry out selective and indicated interventions. The Universal Prevention Curriculum (UPC) delivered by the ICCE model would be the most feasible option for rollout in more countries.

Provided that the accreditation of professionals is feasible, the accreditation of organisations might be easier to carry out since having accredited staff is an important quality criterion for an entire organisation to be accredited. Some initiatives to establish centers of excellence have been proposed, using criteria derived from the CICAD Minimum Quality Standards: continuous quality improvement, monitoring of processes, principles of ethics and staff development, among others. Practically all of the process standards discussed can strongly contribute to developing common accreditation criteria for organisations or services.

Before considering accreditation, most of these standards have to be consolidated, widely accepted and disseminated. And in analogy to the objectives for the implementation Phase of the EDPQS, the existing standards will have to be tested in the field and adapted to regional real-life contexts; not only in Europe (EDPQS) and Canada (CCSA), but also in Latin America, Asia and Africa. This implies also that multilingual materials need to be produced with the local support of national governments or agencies and that basic training has to be offered. Mentor International as an international Non-Governmental Organisation might play a key role in both tasks.

Once the standards have been more widely recognised, used and accepted, some countries would probably be ready and willing to begin testing the feasibility of national (or supra-national) certification/accreditation systems based on some well-consented standards. The next phase of COPOLAD might bring some developments in Latin America in this aspect.

20 http://preventionhub.org 
The main purpose of the COPOLAD standards is however to certify prevention programmes. A possible practical problem in Latin-American countries however might be that, like in Europe, the reality of prevention strategies consists only to a minor extent in implementing programmes, ie. manualised, coherent and structured interventions with multiple sessions. Instead, prevention professionals predominantly carry out single and simple interventions of often-low intensity. These are virtually impossible to certify, since an official certificate of conformity to a quality norm can only be given to a product with standardised parameters (contents and their delivery in this case) and proven fidelity. Interventions that are vaguely defined and implemented with high flexibility should be assessed for (process) quality by means of the standards described here, but would be unlikely to receive an official license for use.

If the certification of programmes is to be taken very seriously, then the standards by UNODC (evidence of interventions in general), those by SPR (criteria for how evidence is created) and some of the process standards (EDPQS or COPOLAD) have to be taken in order to establish solid evidence for each new programme in each nationality (or even on a regional context). A recent proposal by renowned prevention researchers takes this line of thinking further and postulates a central, transparent, evidence-based, context-aware and research oriented approval process for behavioural prevention interventions for Europe. Similarly for medicine approval systems, such a new approval process could be based on four consequential phases evaluating the effect of the following: single components (phase 1); combinations of components (phase 2); the final intervention comprising only components found effective in the previous phases via large, multicenter, randomised trials whenever possible (phase 3); and the long-term effects as well as the effects in different contexts (phase 4) (Faggiano et al. 2014, p.4).

Such a system would certainly be ideal and treats the prevention field with the same caution as medications. It would require at least for Latin America and Europe, very high investments in rigorous evaluation of prevention. In most countries this is unlikely to happen in the near future.

Still, the article by Faggiano et al. highlights an important issue to be clarified for certification: finding a feasible balance between scientific rigour and the promotion of high-quality prevention practice in countries where prevention and prevention research is under funded.

Prevention indeed can be harmful (Moos 2005; Sumnal et al. 2007; Rhule 2005). Probably the ultimate aim of a certification system might be to avoid that: 
- People (and youth in particular) are exposed to ineffective or even harmful interventions and

- such interventions receive funding and support.

If however the requirements for certification are set too high in terms of outcome evaluation (eg. multiple trial assessment of single component effects, of combined effects and of context moderator effects, as Faggiano et al. demand) not a single intervention would pass certification in most countries. This would endanger the objective of improving and promoting prevention, since no intervention could be justified anymore.

It might be useful to soften the criteria, and allow for certification of even those programmes that do not have its own outcome evaluation built in, but consist of implementations of known and recognised evidence-based programmes. For such programmes to be certified they need to prove that appropriate cultural and contextual adaptations have been made and their feasibility been tested in a pilot implementation. A German speaking international closed door expert meeting (Experten und Expertinnengruppe "Kölner Klausurwoche" 2014) arrived to exactly these two definitions of evidence: evidence is either established directly from an intervention's own high quality evaluation or the intervention is based on an established evidence based programme and proves that it is implemented with high fidelity. ${ }^{21}$ A certification process would therefore need at least two different pathways: one for entirely innovative programmes that will need convincing designs for an outcome evaluation; and another for allochthonous programmes with proven efficacy or effectiveness. The latter will have to prove that adaptations and pilot tests have been successfully carried out. The process standards described above in this paper might be useful for this purpose.

Still, many of the possibilities outlined above can only be achieved if main elements of the existing standards are synergistically used together and if the responsible organisations continue to cooperate. Standards on evidence, implementation processes and workforce competencies might then, taken together, create the necessary impression of authority, which is needed to reduce the expectable resistance against the certification of programmes and the accreditation of professionals.

21 http://www.kathonrw.de/fileadmin/primaryMnt/KatHO/Bilder/Bilder_zu_Pressemitteilungen/ab_2014/KoelnerMemorandum_EBSP2014.pdf 


\section{References}

1. Brotherhood A, Sumnall, HR. European drug prevention quality standards - A manual for prevention professionals EMCDDA, ed., Luxembourg: The Publications Office of the European Union 2011.

2. Burkhart G. North American drug prevention programmes: are they feasible in European cultures and contexts? Lisbon: EMCDDA 2013.

3. Campello G. et al International standards on drug use prevention: the future of drug use prevention world-wide. International Journal of Prevention and Treatment of Substance Use Disorders 2014;1(2):6-27. Doi: http://dx.doi.org/10.4038/ijptsud.v1i2.7687

4. Charvát M, Jurystová L, Miovsky M. Four-level model of qualifications for the practitioners of the primary prevention of risk behaviour in the school system. Adiktologie: časopis pro prevenci, léčbu a výzkum závislostí 2012;12(3):190-211.

5. COPOLAD Programa de Cooperación entre América Latina y la Unión Europea en Políticas sobre Drogas, 2014. Calidad y evidencia en reducción de la demanda de drogas. Marco de referencia para la acreditación de programas, Madrid: Entidad de Coordinación y Ejecución (ECE). Experten- und Expertinnengruppe "Kölner Klausurwoche," 2014. Memorandum Evidenzbasierung in der Suchtprävention - Möglichkeiten und Grenzen, Köln.

6. Faggiano F. et al.. Europe Needs a Central, Transparent, and Evidence-Based Approval Process for Behavioural Prevention Interventions. PLoS Med, 2014;11(10), p.e1001740.

Doi: http://dx.doi.org/10.1371/journal.pmed.1001740

7. Hawe P, Shiell A, Riley T.. Theorising interventions as events in systems. American journal of community psychology 2009;43(3-4):26776.

Doi: http://dx.doi.org/10.1007/s10464-009-9229-9

8. Horton, R., 2014. Offline: The third revolution in global health. The Lancet, 383(9929), p.1620.

Doi: http://dx.doi.org/10.1016/S0140-6736(14)60769-8

9. Kellam SG. et al.. The impact of the Good Behavior Game, a universal classroom-based preventive intervention in first and second grades, on high-risk sexual behaviors and drug abuse and dependence disorders into young adulthood. Prevention Science 2014;15 Suppl 1(01):S6-18. 
10. Moos RH. Iatrogenic effects of psychosocial interventions for substance use disorders: prevalence, predictors, prevention. Addiction (Abingdon, England) 2005;100(5):595-604.

Doi: http://dx.doi.org/10.1111/j.1360-0443.2005.01073.x

11. Pavlas Martanová V.. Development of the Standards and the Certification Process in Primary Prevention - An Evaluation Study. Adiktologie: časopis pro prevenci, léčbu a výzkum závislostí 2012;12(3):174188.

12. Rhule DM. Take Care to Do No Harm: Harmful Interventions for Youth Problem Behavior. Professional Psychology: Research and Practice 2005;36(6):618-625.

Doi: http://dx.doi.org/10.1037/0735-7028.36.6.618

13. Ritter A, McDonald D. Illicit drug policy: Scoping the interventions and taxonomies. Drugs: Education, Prevention, and Policy 2008;15(1):15-35.

Doi: http://dx.doi.org/10.1080/09687630701204344

14. Sumnal HR, Sumnall HR, Bellis M. Can health campaigns make people ill? The iatrogenic potential of populationbased cannabis prevention. J Epidemiol Community Health 2007;61(11):930-31.

Doi: http://dx.doi.org/10.1136/jech.2007.060277

\section{Other Key Resources}

- UNODC International Prevention Standards

https://www.unodc.org/unodc/en/prevention/prevention-standards.html

- European Drug Prevention Quality Standards:

http://prevention-standards.eu/

A Prezi explaining them: http://prezi.com/vzppy6-7eqlr/europeandrug-prevention-quality-standards/

- COPOLAD accreditation criteria for prevention programmes in Latin-America (in Spanish)

- https://www.copolad.eu/c/document_library/get_file?uuid=21e37e71b97d-49b0-a068-3bc849500730\& groupId=10157 
- CCSA Prevention Standards

http://www.ccsa.ca/Eng/topics/Children-and-Youth/Drug-PreventionStandards/Pages/default.aspx

- CICAD Minimal Criteria for prevention (in Spanish and English) http://www.cicad.oas.org/

- SPR Standards of evidence http://www.preventionresearch.org/StandardsofEvidencebook.pdf

- Mentor prevention hub www.preventionhub.org 